Research Article

\title{
Breakdown Mechanism of Different Sulphur Hexafluoride Gas Mixtures
}

\author{
E. Onal \\ Electrical Engineering Department, Istanbul Technical University (ITU), Istanbul 34469, Turkey \\ Correspondence should be addressed to E. Onal; eonal@itu.edu.tr
}

Received 15 September 2017; Revised 12 November 2017; Accepted 8 January 2018; Published 1 March 2018

Academic Editor: Santiago Garcia-Granda

Copyright () 2018 E. Onal. This is an open access article distributed under the Creative Commons Attribution License, which permits unrestricted use, distribution, and reproduction in any medium, provided the original work is properly cited.

Sulphur hexafluoride $\left(\mathrm{SF}_{6}\right)$ gas and $\mathrm{SF}_{6}$ gas mixtures are widely used in gas-insulated systems (GIS) because they have good dielectric and thermal properties. Among the various gas mixtures investigated so far, $\mathrm{SF}_{6}$-air, $\mathrm{SF}_{6}-\mathrm{CO}_{2}$, and $\mathrm{SF}_{6}-\mathrm{N}_{2}$ are most used gas mixtures. Also, these mixtures have much technical superiority in GIS. These are nontoxic and nonflammable gases, and they have less sensitivity to nonuniformities and higher liquefaction temperature at high pressure. GIS, switchgears, circuit breakers, and substations are systems that work with alternating current and have nonuniform electric fields. For this reason, in this study the breakdown mechanisms of $0.125,0.5,1$, and $20 \% \mathrm{SF}_{6}$ gas mixtures with rod-plane configuration under AC voltage are investigated and explained breakdown mechanism.

\section{Introduction}

Sulphur hexafluoride $\left(\mathrm{SF}_{6}\right)$ is the most popular insulating gas in the electric power systems such as switchgears, gas circuit breakers, and gas-insulated stations because of having good electrical, thermal, and chemical properties. However, the dielctric strength of $\mathrm{SF}_{6}$ at nonuniform electric field falls drastically to very low values because $\mathrm{SF}_{6}$ is very much sensitive to nonuniformities like impurities and electrode configuration. Since the molecule of $\mathrm{SF}_{6}$ is large and it has small free pathways besides the electrons that are easily attached to $\mathrm{SF}_{6}$ molecules, it has a high dielectric strength. $\mathrm{SF}_{6}$ is a very strong greenhouse gas; for this reason, its global use is restricted on the world. Some greenhouse gases, such as $\mathrm{CO}_{2}$, are naturally found in nature. Some of them are industrial gases like $\mathrm{CO}, \mathrm{CH}, \mathrm{CFCs}, \mathrm{SF}_{6}$, and HCFC-22. Greenhouse gases hold longwave radiation while they allow shortwave radiation to pass to earth. This case causes Earth to warm up. This is an undesirable situation. Today, voluntary programs work to reduce the emission of $\mathrm{SF}_{6}$ into the atmosphere. These programs encourage us to work efficiently at power systems by using less $\mathrm{SF}_{6}$. Our study supports this scientific mission. Besides, $\mathrm{SF}_{6}$ is more expensive than other insulating gases. Thus, it is essential to improve the different dielectric gas or gas mixtures having more appropriate insulating properties, inexpensive, and without greenhouse effect. So, $\mathrm{SF}_{6}$ gas and its mixtures with such as air, nitrogen $\left(\mathrm{N}_{2}\right)$, and carbon dioxide $\left(\mathrm{CO}_{2}\right)$ have been extensively studied [1-6]. The aim of this study is to investigate $\mathrm{SF}_{6}$ mixtures in terms of their electrical strength and to clarify the mechanisms of breakdown. Breakdown properties of $\mathrm{SF}_{6}$ gas mixtures in uniform and quasi-uniform electric field are nearly similar, but their breakdown characteristics in nonuniform electric field depend on various factors such as gas pressure, gas temperature, electrode gap spacing, and gas ratios in the mixture and electrode configuration. The breakdown properties of $\mathrm{SF}_{6}$ gas mixtures in uniform field under impulse and direct voltage have been studied in earlier researches [7-9], but the examination of the characteristics in nonuniform fields is open to research.

Earlier studies have shown that the breakdown voltage of mixtures of $\mathrm{SF}_{6}-\mathrm{N}_{2}$ with below containing $30 \% \mathrm{SF}_{6}$ are less than that of pure $\mathrm{SF}_{6}$ at the pressure of 5 bar. At the same pressure and negative polarity, $0.1 \% \mathrm{SF}_{6}-\mathrm{N}_{2}$ mixture has half dielectric strength compared with that of $100 \% \mathrm{SF}_{6}$. The breakdown voltage of $\mathrm{SF}_{6}-\mathrm{CO}_{2}$ mixtures is higher than that of $\mathrm{SF}_{6}-\mathrm{N}_{2}$ mixtures at the pressure of approximately 4-5 bar, 
while the dielectric strengths of two mixtures are the same at low pressures at negative and positive polarities for direct voltage. However, the strength of negative polarity is always higher than that of positive polarity as in all nonuniform fields. The breakdown voltage of $\mathrm{SF}_{6}-\mathrm{CO}_{2}$ mixtures is higher than that of pure $\mathrm{SF}_{6}$ at some pressures for impulse voltages. As an example at above the pressure of 3 bar, the strengths of $1 \% \mathrm{SF}_{6}-\mathrm{CO}_{2}$ mixtures are slightly higher than those of pure $\mathrm{CO}_{2}$ at negative impulse voltage [10].

\section{Test Setup}

In the experimental study, rod-plane electrode configuration is used to simulate the nonuniform fields in practical systems (Figure 1) because rod-plane electrode system represents the best nonuniformities. The rod electrode with tip radius of $1 \mathrm{~mm}$ and the plane electrode with diameter of $75 \mathrm{~mm}$ are used.

All experiments are performed in the pressure range from 1 bar to 5 bar and at $25 \mathrm{~mm}$ fixed gap spacing. The electrodes are located in a pressure tube as test vessel that has $120 \mathrm{~mm}$ diameter and $600 \mathrm{~mm}$ length. In rod-plane electrode configuration, high voltage is applied to the rod electrode while the plane electrode is earthed (Figure 1). The test vessel is firstly evacuated and then filled with the gas mixtures to the pressure of 5 bar. For the $50 \mathrm{~Hz}$ AC tests, $100 \mathrm{kVrms}$, and $5 \mathrm{kVA}$, a high-voltage test transformer is used. A capacitive divider and voltmeter are used to measure the applied high voltage. Experiments were carried out in Istanbul Technical University (ITU) High Voltage Laboratory (Figure 2).

In this study, the breakdown voltages of $\mathrm{CO}_{2}, \mathrm{~N}_{2}$, air, $\mathrm{SF}_{6}$, and the mixtures of $\mathrm{SF}_{6}-\mathrm{CO}_{2}, \mathrm{SF}_{6}-\mathrm{N}_{2}$, and $\mathrm{SF}_{6}$-air with $20,1,0.5$, and $0.125 \%$ of $\mathrm{SF}_{6}$ are measured from 1 bar to 5 bar with 1 bar steps at rod-plane electrode configuration.

\section{Experimental Results}

$\mathrm{SF}_{6}$ gas mixtures are lot in nature and cheap. These gas mixtures are selected as air, $\mathrm{N}_{2}$, and $\mathrm{CO}_{2}$. The breakdown voltages of these gas mixtures depending on pressure are shown in Figures 3-5, respectively. Since the decompositions of these gas mixtures under pressure are important, air, $\mathrm{N}_{2}$, and $\mathrm{CO}_{2}$ gases are selected in this study.

As seen in Figures 3-5, a little bit addition of $\mathrm{SF}_{6}$ to these gases has significantly increased the breakdown voltage values. The high breakdown of voltage means that high electrical strength is very important in insulation technique in power systems. As can be seen from the above discussion, dielectric strength of only $\mathrm{N}_{2}, \mathrm{CO}_{2}$, and air increases linearly with increasing pressure, whereas the breakdown voltages of $\mathrm{SF}_{6}$ mixtures are approximately the same at a pressure of higher than 4 bar. The mixture having the lowest dielectric strength among the three mixtures is the mixture of $\mathrm{SF}_{6}-\mathrm{N}_{2}$. The effect of $\mathrm{N}_{2}$ on breakdown strength is less than that of air and $\mathrm{CO}_{2}$. The reason for this is electron mobility and ionization energy. The gas additive to $\mathrm{SF}_{6}$ affects the charge density and the width of streamer between the electrodes. Besides, electron mobility affects the delay of leader streamer

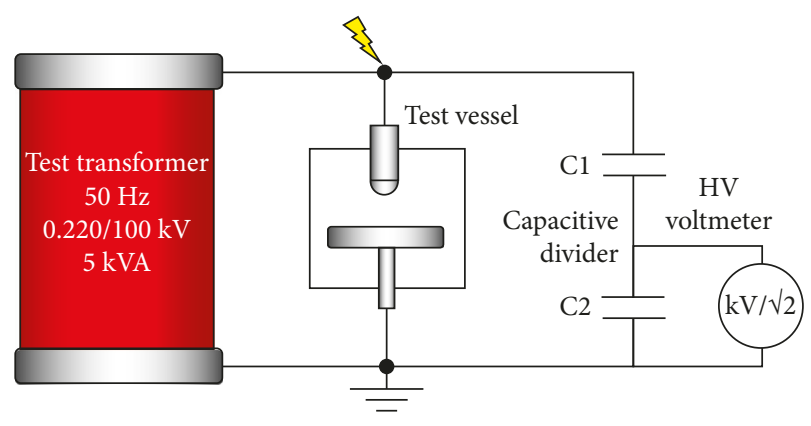

Figure 1: Test setup.

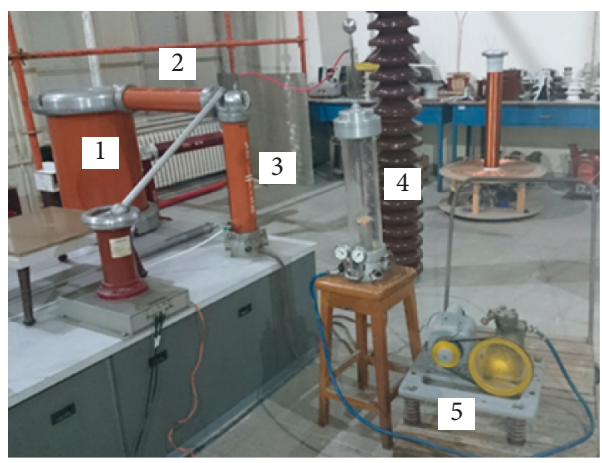

FIgURE 2: Test setup at high voltage laboratory of ITU. (1) Test transformer; (2) current limiting resistor; (3) capacitive divider; (4) test vessel; (5) vacuum pump.

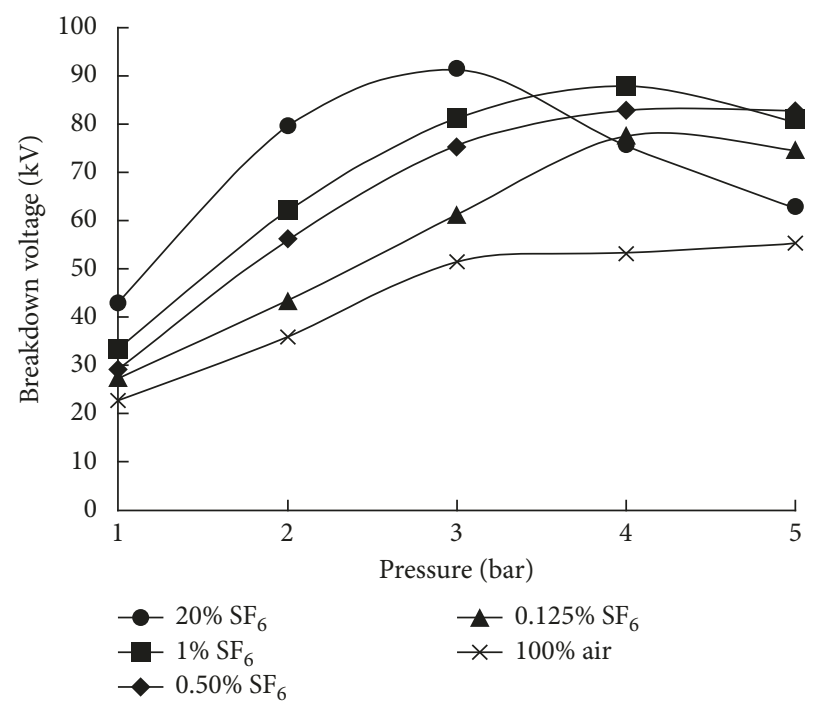

FIGURE 3: Changing of breakdown voltage with gas pressure for $\mathrm{SF}_{6}$-air mixtures.

in gas mixtures. For this reason, the breakdown mechanisms of $\mathrm{SF}_{6}$ gas mixtures are different from each other. It is known that the breakdown mechanism of $\mathrm{SF}_{6}$ is streamer and stepped leader breakdowns. As the $\mathrm{SF}_{6}$ ratio increases, the stepped leader mechanism is valid. The leader step time is the interval time between two consecutive leader steps and is 


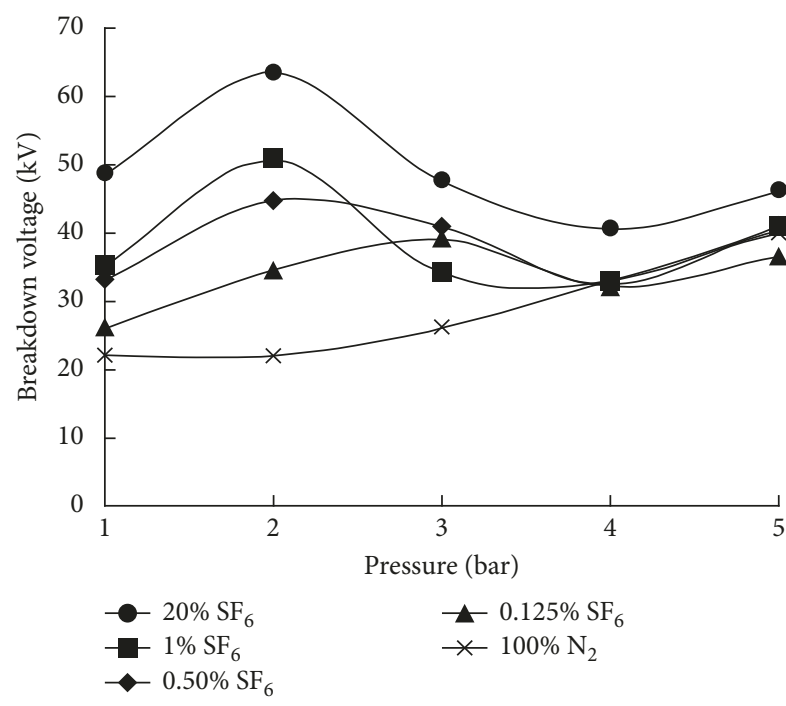

FIGURE 4: Changing of breakdown voltage with gas pressure for $\mathrm{SF}_{6}-\mathrm{N}_{2}$ mixtures.

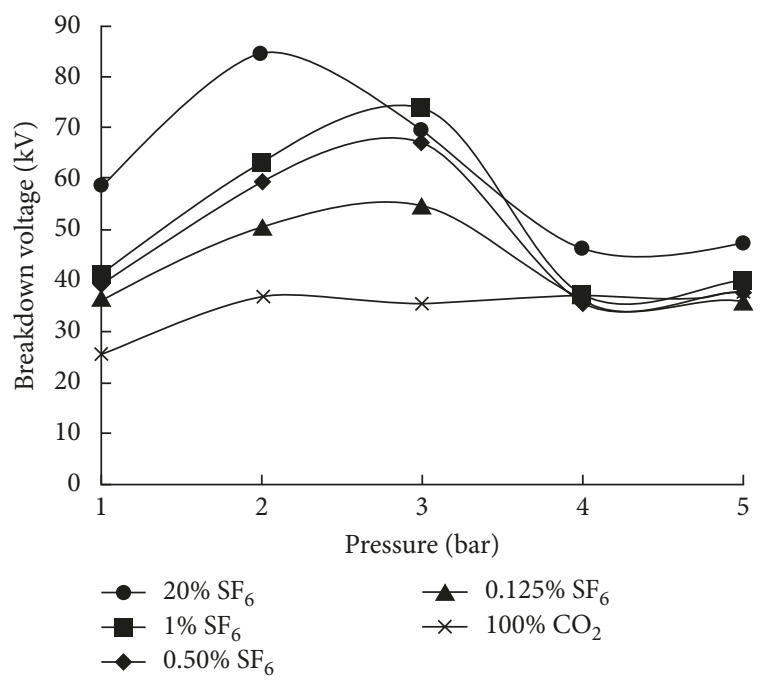

Figure 5: Changing of breakdown voltage with gas pressure for $\mathrm{SF}_{6}-\mathrm{CO}_{2}$ mixtures.

an important parameter in $\mathrm{SF}_{6}$ gas mixtures. It is a decisive factor in the development of breakdown and streamer. It depends on the $\mathrm{SF}_{6}$ gas mixture ratio, pressure, and voltage and is represented by

$$
t_{s}=\frac{K}{(p U)},
$$

where $p$ is the gas pressure, $U$ is the voltage applied between the electrodes, and $K$ is the constant depending on the $\mathrm{SF}_{6}$ gas mixtures ratio. For $\mathrm{SF}_{6}-\mathrm{N}_{2}$ mixtures, $K$ is smaller than that for $\mathrm{SF}_{6}-\mathrm{CO}_{2}$ and $\mathrm{SF}_{6}$-air mixtures [11]. These mixtures have many superiorities compared to pure $\mathrm{SF}_{6}$. The addition of relatively small amount of $\mathrm{SF}_{6}$ to nitrogen, carbon dioxide, and air causes a significant increase in dielectric strength. As an example, breakdown voltage of $0.125 \%$ of $\mathrm{SF}_{6}$-air is 1.5 times higher than that of pure air at the pressure of 4 bar.

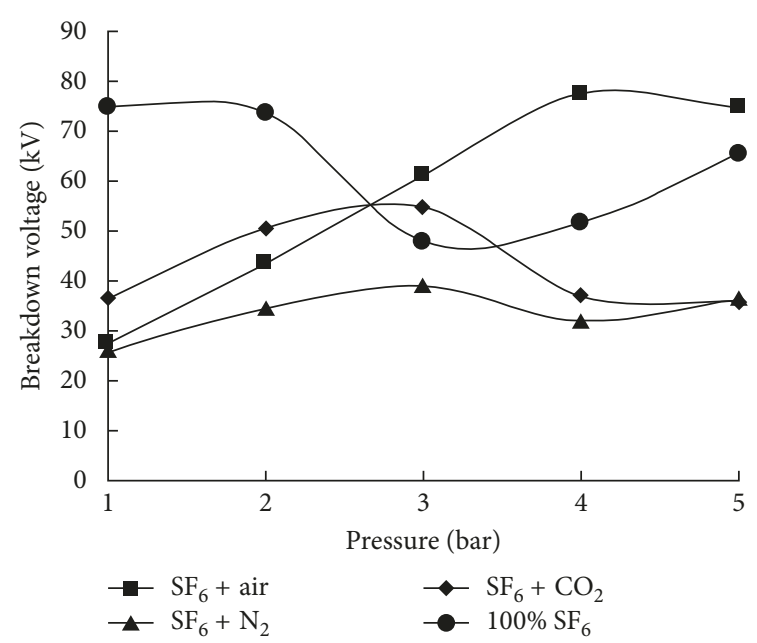

FIGURE 6: Changing of breakdown voltage with gas pressure for $100 \% \mathrm{SF}_{6}$ and $0.125 \% \mathrm{SF}_{6}$ mixture.

Figure 6 gives the variation of breakdown voltage of pure $\mathrm{SF}_{6}$ and $0.125 \% \mathrm{SF}_{6}$ mixtures depending on gas pressure.

As seen in Figure 6, for $25 \mathrm{~mm}$ rod-plane gap, breakdown voltage of pure $\mathrm{SF}_{6}$ is about 3 times higher than that of air, $\mathrm{N}_{2}$, and $\mathrm{CO}_{2}$ at pressure of 1 bar. However, as the gas pressure is increased to about 3.5 bar, breakdown voltage of $\mathrm{SF}_{6}$ is $20 \%$ less than that of air. At the pressure of 5 bar, pure $\mathrm{SF}_{6}$ is $20 \%$ higher than that of air. The breakdown voltages of $\mathrm{CO}_{2}$ and $\mathrm{N}_{2}$ are lower than that of $\mathrm{SF}_{6}$. As seen in Figures $3-5$, the breakdown voltages of pure $\mathrm{N}_{2}, \mathrm{CO}_{2}$, and air are increased approximately linear with pressure; however, pure $\mathrm{SF}_{6}$ has a maximum-minimum breakdown characteristic. The experiments have shown that addition of relatively small amount of $\mathrm{SF}_{6}$ to air, $\mathrm{N}_{2}$, and $\mathrm{CO}_{2}$ causes important increase in dielectric strength. As an example, the breakdown voltage of $0.125 \mathrm{SF}_{6}$-air is approximately twice than that of pure $\mathrm{SF}_{6}$ at pressure of 3.5 bar. Breakdown strength of $\mathrm{SF}_{6}-\mathrm{CO}_{2}$ is higher than that of other mixtures at the pressure range of 1-3 bar, but $\mathrm{SF}_{6}$-air mixtures are better at higher pressures. From experimental results, $\mathrm{SF}_{6}$-air mixtures show less degree of saturation at higher pressure when compared to $\mathrm{SF}_{6}-\mathrm{N}_{2}$ and $\mathrm{SF}_{6}-\mathrm{CO}_{2}$ mixtures. Since breakdown phenomena occur in the positive polarity, the breakdown mechanism explanations about AC voltage are related to the mechanism of positive impulse and direct voltage. It is needed to mention the breakdown mechanism to explain the abnormal case. In this study, the electrode gap is of $25 \mathrm{~mm}$. The breaker contact spacings used in practice are in these ranges, and most of them have nonuniform fields. The best model to simulate these nonuniformities is the rod-plane electrode configuration. The contact ranges of the switchgears vary between 1 and $10 \mathrm{~cm}$ according to the nominal voltage and current. However, for GIS, these gaps may be $25-30 \mathrm{~cm}$, but the investigations show that they have the same breakdown mechanism. As is known, there are two types of breakdown mechanisms in gas mixtures. These are Townsend theory and streamer theory. Townsend breakdown mechanism is valid for smaller product of the gas pressure $(\mathrm{mmHg})$ and the electrode gap $(\mathrm{cm})$ of $500 \mathrm{mmHg} \cdot \mathrm{cm}$. 
Especially at large electrode gap spacing, Townsend theory is insufficient to explain the discharge mechanism. Streamers in short gaps develop with the increase of the applied voltage until spark takes place. Physical and chemical interpretations can be made about some of the characteristic cases. Maximum-minimum behaviour due to gas pressures is indicated as abnormal discharges in the literature. The reason why breakdown voltage has maximum-minimum characteristics according to the pressure is related to the following situations: nonuniform field, $\mathrm{SF}_{6}$ gas, positive polarity voltage, or AC voltage. The breakdown voltage increases with the increasing pressure. This is a very normal situation. If the ambient has nonuniform field, $\mathrm{SF}_{6}$ gas and AC voltage as in our system, variation of breakdown voltage has the maximum-minimum characteristic. Earlier research has shown that the rise time duration of the test voltage increases when the possibility of effective corona stabilization raises. This behaviour is significant for gas pressures of 1 and 2 bar. Also for longer rise time duration and higher gas pressure of 3 bar, the effect of corona stabilization is weak. This means with high gas pressure and the low leader inception voltage, the breakdown strength reduces. This period is the diffusion time of a thermic wave. This wave starts from the high-field electrode system and spreads the whole gap. The temperature rises to as high as $900^{\circ} \mathrm{K}$ under $\mathrm{AC}$ voltages in the ionization region. So it is important to reduce the temperature at this region. The electrical strength rises at point and the spark becomes easily. This theory is investigated as "a narrow jet model" at dc voltage by R. S. Sigmond. As a result, the diffusion and heat convection in the pressure range of 2-3 bar decrease, and the thermal ionization brought by the electron avalanche plays an important role. In this case, breakdown follows the shortest ionized path. The reason of this abnormal breakdown is the opposite effect of ionization and diffusion phenomena related to breakdown voltage. Diffusion is reduced by the pressure increase; this case leads to increase of space charge and electrical strength. This phenomenon causes the breakdown voltage to decrease. Ionization effect is active at positive polarity since heavy positive ions cannot reach the opposite electrode easily, and the positive ions are collected at the tip of the rod electrode, so they shorten the space gap. Diffusion also causes the thermal convection, and the breakdown follows the shortest way between the electrodes. As seen in Figures 3-5, the maximum point shifts to the right as the $\mathrm{SF}_{6}$ ratio decreases [12]. This is also an abnormal condition in $\mathrm{SF}_{6}$ gas mixtures for nonuniform fields. Small $\mathrm{SF}_{6}$ mixtures may fall to a minimum at higher pressures. Ionization and diffusion events are also effective here.

\section{Conclusion}

The test results show that $\mathrm{SF}_{6}$ mixtures have an important electrical strength at the pressure range of $1-4$ bar according to electrical strengths of pure air, $\mathrm{N}_{2}$, and $\mathrm{CO}_{2} . \mathrm{SF}_{6}$ has disadvantage properties particularly between the pressure of 2-3 bar, which is the range of use of electrical devices, but $\mathrm{SF}_{6}$ gas mixtures have many superiorities compared to pure $\mathrm{SF}_{6}$. These mixtures are technically and economically attractive alternatives. These mixtures are cheaper and more environmentally friendly than pure $\mathrm{SF}_{6}$. It is important to check the chemical decomposition of $\mathrm{SF}_{6}$ mixture under electrical stress at various mixture ratios. Further studies will focus on decomposition of $\mathrm{SF}_{6}$ mixtures under pressure at ambient with water vapour and oxygen because at this case decomposition of $\mathrm{SF}_{6}$ forms as solid state.

\section{Conflicts of Interest}

The author declares that he has no conflicts of interest.

\section{References}

[1] R. J. Brunt and M. Misakian, "Mechanism for inception of DC and $60 \mathrm{~Hz} \mathrm{AC}$ corona in $\mathrm{SF}_{6}$," IEEE Transactions on Dielectrics and Electrical Insulations, vol. 17, no. 2, pp. 106-120, 1982.

[2] N. H. Malik and A. H. Qureshi, "Breakdown mechanism in sulphur hexafluoride," IEEE Transactions on Dielectrics and Electrical Insulations, vol. 13, no. 3, pp. 135-145, 1978.

[3] Y. Qiu and D. M. Xiao, "Dielectric strength of the $\mathrm{SF}_{6} \mathrm{CO}_{2}$ gas mixture in different electric fields," in Proceedings of the 9th International Symposium on High Voltage Engineering, Graz, Austria, August 1995.

[4] X. Dengming, Gas Discharge and Gas Insulation, vol. 6, Springer, Berlin, Heidelberg, Germany, 2016.

[5] E. Onal, "Neural networks for breakdown voltage estimation of various gas mixtures," International Journal of Engineering Intelligent Systems for Electrical Engineering and Communications, vol. 73, 2008.

[6] A. M. Casanovas, L. Vial, I. Coll, M. Storer, J. Casanovas, and R. Clavreul, "Decomposition of $\mathrm{SF}_{6}$ under $\mathrm{AC}$ and $\mathrm{DC}$ corona discharges in high pressure $\mathrm{SF}_{6}$ and $\mathrm{SF}_{6} / \mathrm{N}_{2}(10-90 \%)$ mixtures," in Gaseous Dielectrics VIII, Springer, New York, NY, USA, 1998.

[7] Y. Fu, M. Rong, K. Yang et al., "Calculated rate constants of the chemical reactions involving the main by products $\mathrm{SO}_{2} \mathrm{~F}$, $\mathrm{SOF}_{2}, \mathrm{SO}_{2} \mathrm{~F}_{2}$ of $\mathrm{SF}_{6}$ decomposition in power equipment," Journal of Physics D: Applied Physics, vol. 49, no. 15, p. 1555502, 2016.

[8] H. Okubo and A. Beroual, "Recent trend and future perspectives in electrical insulation techniques in relation to sulphur hexafluoride substitutes for high voltage electric power equipment," IEEE Transactions Electrical Insulation Magazine, vol. 27, no. 2, pp. 34-42, 2011.

[9] M. Rabie and C. Franck, "Predicting the electric strength of proposed $\mathrm{SF}_{6}$ replacement gases by means of density functional theory," in Proceedings of the 18th International Symposium on High Voltage Engineering (ISH'13), Seoul, Republic of Korea, August 2013.

[10] Z. Li, S. Chen, S. Gong, B. Feng, and Z. Zhou, "Theoretical study on gas decomposition mechanism of $\mathrm{SF}_{6}$ by quantum chemical calculation," Computational and Theoretical Chemistry, vol. 1088, pp. 24-31, 2016.

[11] W. Gu, Q. Zhang, and Y. Qiu, "Leader step time and low probability impulse breakdown voltage measured in SF6," in Gaseous Dielectrics VIII, Springer, New York, NY, USA, 1998.

[12] D. Han, T. Lin, and G. Zhang, " $\mathrm{SF}_{6}$ gas decomposition analysis under point to plane $50 \mathrm{~Hz}$ AC corona discharge," IEEE Transactions on Dielectrics and Electrical Insulation, vol. 22, no. 2, pp. 799-805, 2015. 


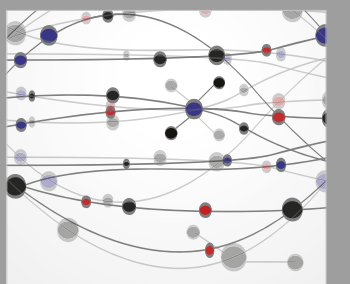

The Scientific World Journal
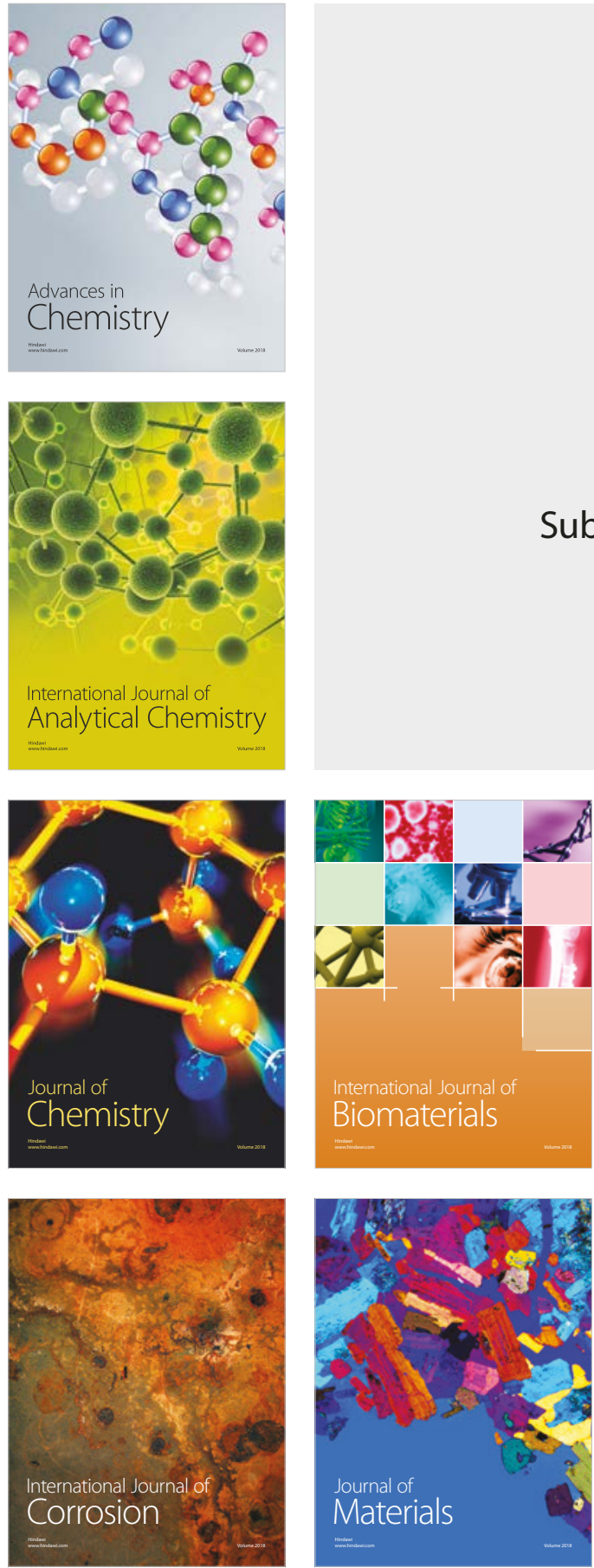

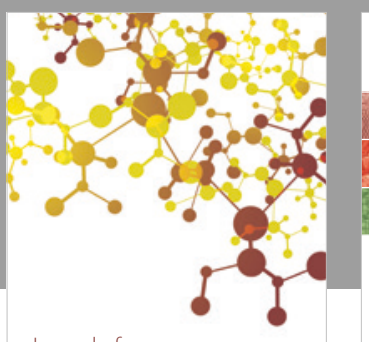

Journal of

Applied Chemistry
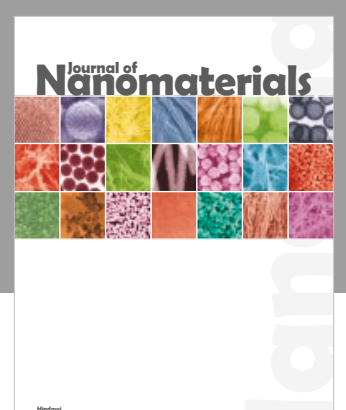

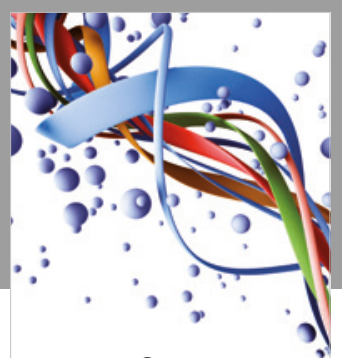

Scientifica

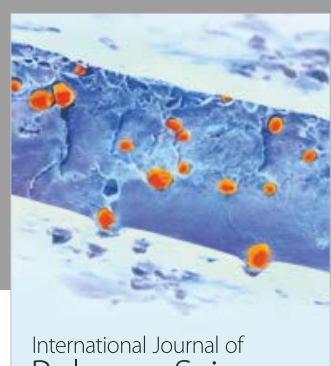

Polymer Science

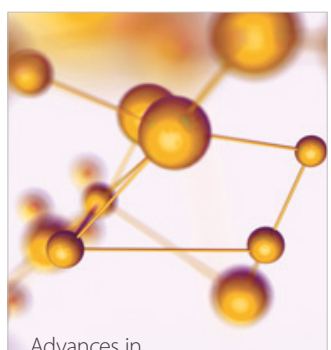

Physical Chemistry
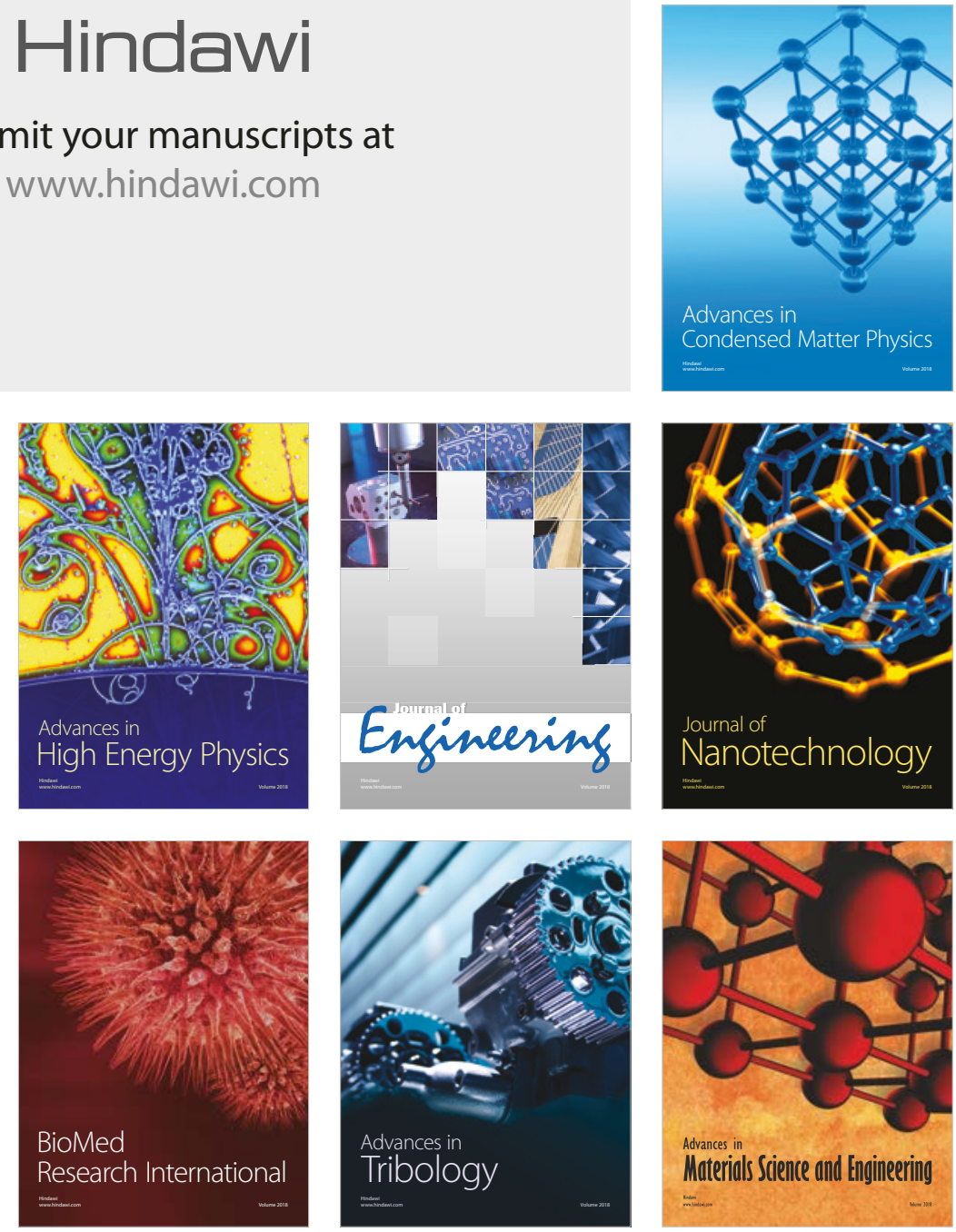